\title{
Preparation of Microcapsules Containing Erythritol with Interfacial Polycondensation Reaction by Using the (W/0) Emulsion
}

\author{
Yasuhito Hayashi', Kiyomi Fuchigami ${ }^{2}$, Yoshinari Taguchi', Masato Tanaka ${ }^{1 *}$ \\ ${ }^{1}$ Graduate School of Science and Technology, Niigata University, Niigata, Japan \\ ${ }^{2}$ Department of Research \& Development, Shofu Inc., Kyoto, Japan \\ Email: ${ }^{*}$ tanaka@eng.niigata-u.ac.jp
}

Received 23 October 2014; revised 13 November 2014; accepted 4 December 2014

Copyright (C) 2014 by authors and Scientific Research Publishing Inc.

This work is licensed under the Creative Commons Attribution International License (CC BY). http://creativecommons.org/licenses/by/4.0/

(c) (i) Open Access

\begin{abstract}
It was tried to microencapsulate erythritol as a phase change material with the interfacial polycondensation reaction method by using the $(\mathrm{W} / 0)$ emulsion and to characterize the microcapsules prepared. In the experiment, toluene diisocyanate, diphenyl methane diisocyanate and hexamethylenediisocyanate were used to form the polyurethane shell and the effects of them on the heat storage density and the microencapsulation efficiency were investigated. Furthermore, the effect of supercooling prevention agent on the phase change behavior of erythritol was investigated. The microcapsules prepared with toluendiisocyanate monomer showed the highest heat storage density and the higher microencapsulation efficiency. Considerable supercooling phenomenon in the microcapsule was observed and prevented to a certain degree by addition of potassium dihydrogen phosphate and calcium sulfate as the supercooling prevention agent.
\end{abstract}

\section{Keywords}

Phase Change Material, Erythritol, Polyurethane Microcapsules, Latent Heat Storage, Super Cooling Prevention Agent

\section{Introduction}

Many kinds of microcapsules have been developed and applied to the various fields such as cosmetics, drugs, textile, food industry, information, information recording materials and so on [1]-[4].

For an example, many kinds of microcapsules containing the phase change material (PCM) have been pre-

${ }^{*}$ Corresponding author.

How to cite this paper: Hayashi, Y., Fuchigami, K., Taguchi, Y. and Tanaka, M. (2014) Preparation of Microcapsules Containing Erythritol with Interfacial Polycondensation Reaction by Using the (W/O) Emulsion. Journal of Encapsulation and Adsorption Sciences, 4, 132-141. http://dx.doi.org/10.4236/jeas.2014.44014 
pared and applied to the latent heat storage technology [5]-[12].

The microcapsules applied in this field have been prepared with the chemical preparation methods such as the in-situ polymerization method, the interfacial polycondensation method and the suspension polymerization method. On applying the microcapsules to the latent heat storage technology, many kinds of paraffin waxes, fatty acids and fatty alcohols have been adopted as PCM because of the wide range of melting points [13]-[17]. However, as these materials are inflammable, the microcapsules containing these materials as PCM can not be largely used in the fields such as the interior materials of buildings and cars and textiles.

For this, it is strongly desired that the PCMs such as the inorganic compound hydrates and polysaccharides are microencapsulated and applied. Meanwhile, as these PCMs are water soluble, the microcapsules have to be prepared by using the reverse dispersion system such as the (W/O) emulsion or the $(\mathrm{S} / \mathrm{O})$ dispersion.

Stritih, et al. tried to apply the calcium chloride hexahydrate as a PCM to the building materials [18].

Tyagi, et al. performed the thermal cycle testing of calcium chloride hexahydrate as a possible PCM [19]. But they did not describe the microencapsulation method in detail.

Tingyu, et al. tried to microencapsulate sodium phosphate dodecahydrate as a PCM with in situ polymerization and solvent evaporation method and investigated the thermal properties of microencapsulated PCM [20].

However, it seems that there are no fundamental works with regard to the preparation of microcapsules containing the water soluble PCMs by the interfacial polycondensation reaction method.

Taking these things into consideration, it was tried to microencapsulate erythritol as a water soluble PCM with the interfacial polycondensation reaction method by using the (W/O) emulsion.

The purposes of this study are to investigate whether the microcapsules containing the aqueous solution of erythritol as the water soluble PCM can be prepared or not, to obtain the fundamental informations for preparing the microcapsules with the interfacial polycondensation reaction method by using the (W/O) emulsion and to characterize the microcapsules.

\section{Experimental}

\subsection{Materials}

Materials used to prepare the microcapsules containing erythritol were as follows.

Polyethyleneglycol 600 (PEG) was used as the water soluble monomer and isocyanate monomers (toluene diisocyanate: TDI, diphenyl methane diisocyanate: MDI, hexamethylenediisocyanate: HDI) were used as the oil soluble monomers. Erythritol was adapted as a water soluble PCM. The corn oil was used as the continuous phase and the additional phase, respectively. Polyglycerolpolyricinol (Poem PR-100: Riken Vitamin Co., Ltd, Japan) was used as an oil soluble surfactant which was dissolved in the continuous phase beforehand. Potassium dihydrogen phosphate and calcium sulfate were added as the supercooling prevention agents. These materials except PR-100 were from Wako Pure Chemicals (Tokyo, Japan).

\subsection{Preparation of Microcapsules}

Figure 1 shows the flow chart for preparing the microcapsules containing erythritol together with the schematic diagram of experimental apparatus. The six bladed disc turbine with the diameter of $5.0 \mathrm{~cm}$ was used to form the (W/O) emulsion.

Erythritol and PEG of the given weight were dissolved in distilled water to prepare the dispersed water phase. The dispersed water phase was added into the continuous oil phase (corn oil) dissolving Poem PR-100 and stirred for $10 \mathrm{~min}$ to form the (W/O) emulsion under the conditions of the revolution velocity of $300 \mathrm{rpm}$ and $70^{\circ} \mathrm{C}$.

Then, the additional corn oil dissolving isocyanate monomer was added into the (W/O) emulsion at the pouring velocity of $150 \mathrm{ml} / \mathrm{min}$ with the microsyringe. The interfacial polycondensation reaction was performed at $70^{\circ} \mathrm{C}$ for $24 \mathrm{~h}$. The microcapsules prepared thus were washed in distilled water, separated by the filtration paper, dried at room temperature and then, characterized. In this fundamental experiment, isocyanate species and the concentration of PEG were changed. The experimental conditions were shown in Table 1.

\subsection{Characterization}

\subsubsection{Heat Storage Density}

The heat storage density of microcapsules was estimated by differential scanning calorimeter (DSC-50: Shimazu 
Table 1. Experimental conditions.

\begin{tabular}{|c|c|}
\hline Dispersed water phase & \\
\hline Distilled Water & $5.0 \mathrm{~g}$ \\
\hline Erythritol & $5.0 \mathrm{~g}$ \\
\hline PEG & $0.5-6.0$ g $\left(9.0\right.$ wt $\%-55$ wt $\left.\% \mathrm{H}_{2} \mathrm{O}\right)$ \\
\hline \multicolumn{2}{|l|}{ Oil phase } \\
\hline Corn Oil & $98.5 \mathrm{~g}$ \\
\hline Poem PR-100 & $1.5 \mathrm{~g}$ (1 wt\% oil phase) \\
\hline \multicolumn{2}{|l|}{ Additional phase } \\
\hline Corn Oil & $72.0 \mathrm{~g}$ \\
\hline Poem PR-100 & $0.79 \mathrm{~g}$ (1 wt\% oil phase) \\
\hline Isocyanete (TDI, MDI, HDI) & $6.0 \mathrm{~g}$ (3.36 wt\% oil phase) \\
\hline Pouring Velocity & $150 \mathrm{ml} / \mathrm{min}$ \\
\hline \multicolumn{2}{|l|}{ Formation of (w/o) emulsion } \\
\hline Time & $10 \mathrm{~min}$ \\
\hline Impeller speed & $300 \mathrm{rpm}$ \\
\hline Temperature & $70^{\circ} \mathrm{C}$ \\
\hline \multicolumn{2}{|l|}{ Interfacial Polycondensation } \\
\hline Time & $24 \mathrm{~h}$ \\
\hline Impeller speed & $300 \mathrm{rpm}$ \\
\hline Temperature & $70^{\circ} \mathrm{C}$ \\
\hline
\end{tabular}

Calcium Sulfate

Calcium Phosphate

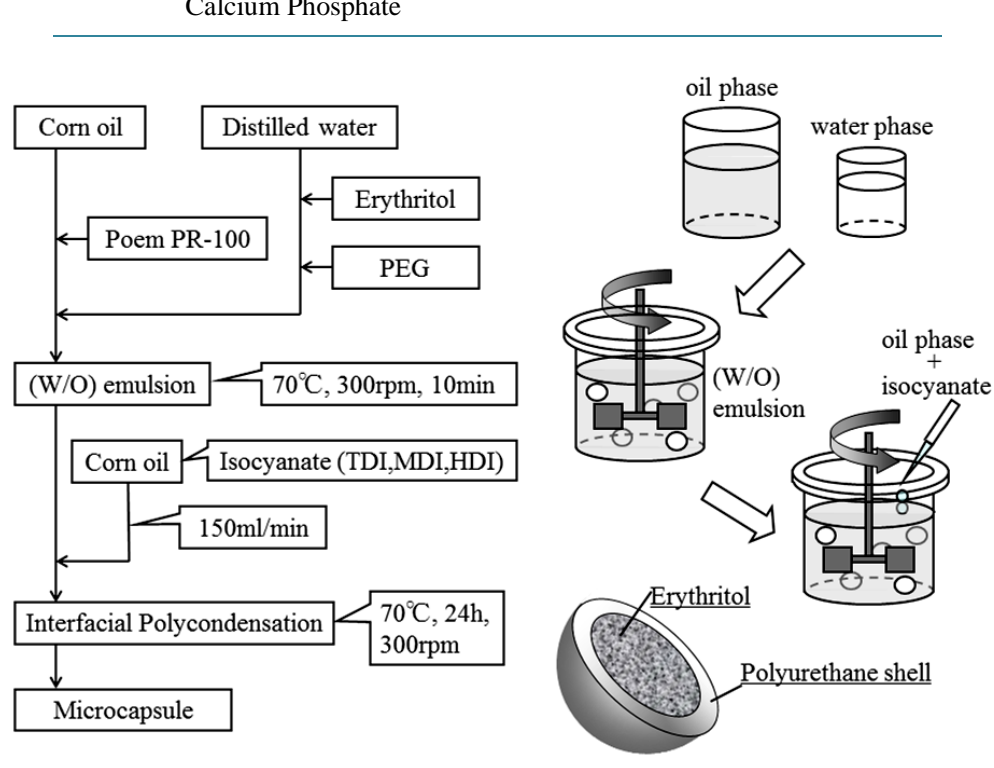

Figure 1. Flow chart for preparing microcapsules. 
Seisakusho, Co., Ltd, Kyoto, Japan).

\subsubsection{Microencapsulation Efficiency}

The microencapsulation efficiency $(\mathrm{Y})$ of microcapsules prepared by changing the experimental conditions was calculated by the following Equation (1).

$$
\mathrm{Y}(\%)=\frac{D_{C}}{D_{E} \cdot W_{E} /\left(M_{E}+M_{P E G}+M_{I S O}\right)} \times 100
$$

where, $D_{C}, D_{E}, M_{E}, M_{P E G}$ and $M_{I S O}$ were the heat storage density of microcapsules, the heat storage density of erythritol, the weight of erithritol, the weight of PEG and the weight of isocyanate, respectively.

\subsubsection{Mechanical Strength and Shock Absorbance}

The mechanical strength and the degree of shock absorbance of microcapsules were measured by the hand-made instrument for measuring the mechanical strength as shown in Figure 2. Namely, the microcapsules were kept on the specimen support. The attachment was raised and lowered automatically. And then, the moving length of attachment and the load until the microcapsule was broken were measured. The mechanical strength and the degree of shock absorbance were estimated by the load and the moving length, respectively.

\section{Results and Discussion}

\subsection{Effects of Isocyanate Species and Concentration of PEG}

Figure 3 shows the SEM photographs of microcapsules without and with erythritol prepared by using each isocyanate. From these photographs, it was found that the microcapsules without and with erithritol could be prepared by each isocyanate and were the core-shell structure with the rough surface. Furthermore, erythritol was observed in the microcapsules. However, it is difficult to find the difference in the inner structures of microcapsules prepared without and with erythritol.

Figure 4(a) shows the dependence of mean diameters (Dp) of microcapsules on the concentration ( $\mathrm{C}_{\mathrm{PEG}}$ ) of PEG and the isocyanate species. As an example, the SEM photographs of microcapsules prepared with TDI by changing the concentration of PEG are shown in Figure 4(b). In the case of TDI and MDI, the mean diameter slightly increased with the concentration of PEG and become constant. However, in the case of HDI, the mean diameter largely increased with the concentration of PEG. As the viscosity of water phase droplet increases with the concentration of PEG, the water droplets become larger due to increase in the viscous energy against the destructive force [21] [22]. The increase in the mean diameter of microcapsules prepared with HDI may be due to the following results. It is well known that the faster the reaction velocity of interfacial polycondensation reaction becomes, the more stable the emulsion become and the spherical sound microcapsules can be prepared. As the reaction velocity for HDI is slower, coalescence between the water droplets may easily occur and the larger

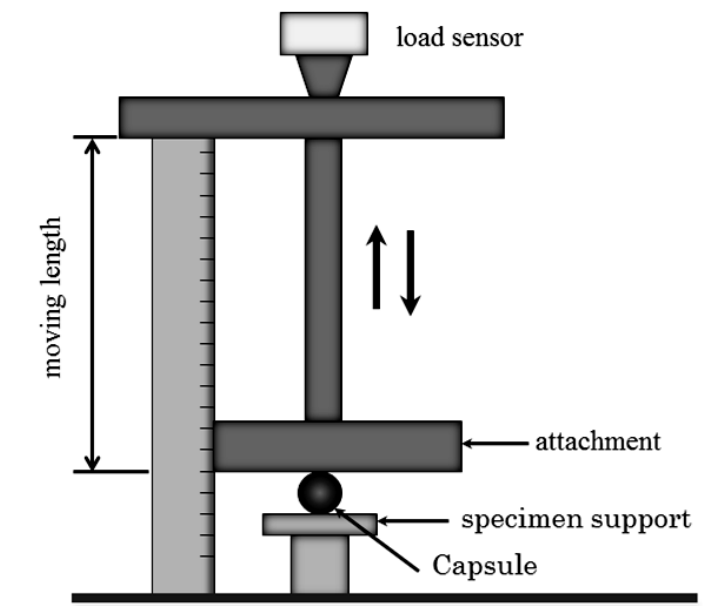

Figure 2. Instrument for measuring mechanical strength. 


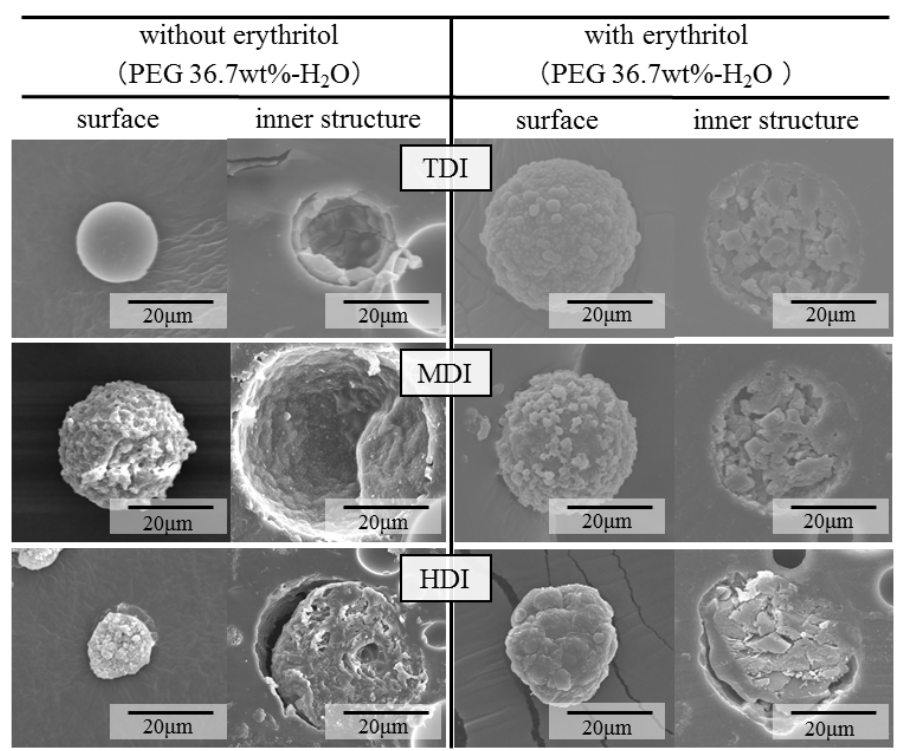

Figure 3. SEM Photographs of microcapsules.

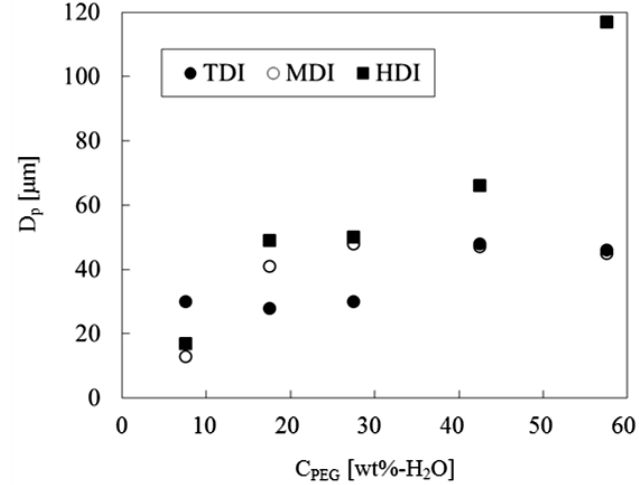

(a)

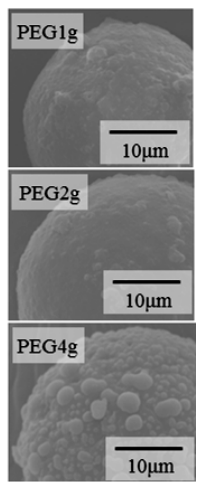

(b)

Figure 4. Dependence of mean diameter on concentration of PEG and isocyanate species.

irregular microcapsules may be prepared. Contrary to this, as the reaction velocities for TDI and MDI are faster, the microcapsule shell may rapidly grow and the sound microcapsules may be prepared. Also, it was found that the larger the concentration of PEG become, the more rough the surface of microcapsules become.

Figure 5 and Figure 6 show the dependences of heat storage density and the microencapsulation efficiency (Y) on the concentration of PEG and the isocyanate species, respectively. The heat storage density for TDI increased, become maximum (ca. $82 \mathrm{~J} / \mathrm{g}$ at $\mathrm{C}_{\mathrm{PEG}}=28 \mathrm{wt} \%$ ) and then, decreased with the concentration of PEG. On the other hand, the heat storage densities for HDI and MDI slightly increased, become maximum and then, gradually decreased with the concentration of PEG. The maximum heat storage density for TDI was larger than those for MDI and HDI.

On the other hand, the microencapsulation efficiency for TDI and MDI increased, become maximum $(\mathrm{Y}=$ $82 \%$ at $\mathrm{C}_{\mathrm{PEG}}=28 \mathrm{wt} \%$ for TDI, $\mathrm{Y}=64 \%$ at $\mathrm{C}_{\mathrm{PEG}}=28 \mathrm{wt} \%$ for $\mathrm{MDI}$ ) and then, decreased with the concentration of PEG. The microencapsulation efficiency for HDI changed from $Y=15 \%$ to $30 \%$ with the concentration of PEG. As the microcapsules with TDI could be stably prepared, the maximum microencapsulation efficiency for TDI may become larger than those for HDI and MDI. The heat storage density and the microencapsulation efficiency may be dependent on the stability of (W/O) emulsion during the microencapsulation process.

The effects of isocyanate monomer species and the concentration of PEG are summarized in Table 2. 


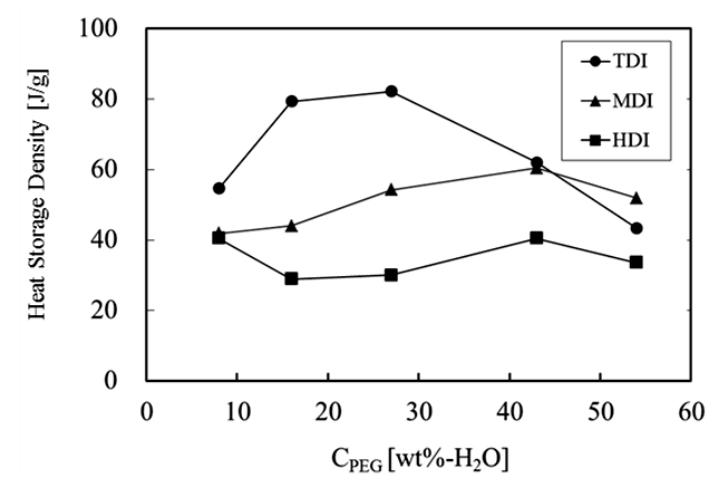

Figure 5. Dependence of heat storage density on concentration of PEG and isosyanate species.



Figure 6. Dependence of microencapsulation efficiency on concentration of PEG and isosyanate species.

\section{Table 2. Summary of results.}

\begin{tabular}{ccc}
\hline & Heat storage density & Microencapsulation efficiency \\
\hline TDI & $53-82 \mathrm{~J} / \mathrm{g}$ & $55 \%-82 \%$ \\
MDI & $41-50 \mathrm{~J} / \mathrm{g}$ & $41 \%-50 \%$ \\
HDI & $30-40 \mathrm{~J} / \mathrm{g}$ & $30 \%-40 \%$ \\
\hline
\end{tabular}

Figure 7 shows the dependences of the mechanical strength and the degree of shock absorbance of microcapsules on the isocyanate species. From Figure 7(a), the microcapsules prepared with TDI and MDI were found to be stronger, because the microcapsules showed the sharp slop on the load vs distance relation. From Figure 7(b), the microcapsules of the diameters of $10 \mu \mathrm{m}$ and $200 \mu \mathrm{m}$ prepared with TDI were found to have the larger degree of shock absorbance, because the moving lengths were longer than others.

Figure 8 shows the DSC curves for erythritol (a) and the microcapsules prepared with each isocyanate (b). The DSC curve for erythritol shows the endothermic peak at $121^{\circ} \mathrm{C}$ and the exothermic peak at $21^{\circ} \mathrm{C}$. The endothermic peak at $121^{\circ} \mathrm{C}$ is slightly higher than $119^{\circ} \mathrm{C}$ in the reference value, but the exothermic peak at $21^{\circ} \mathrm{C}$ is lower than $43^{\circ} \mathrm{C}$ in the reference value. These phenomena may be due to supercooling.

Meanwhile, the DSC curves for the microcapsule prepared with each isocyanate show only the endothermic peak. These results may be due to the supercooling phenomenon occured in the small hollow volume of microcapsule and the effect of reaction remains such as PEG. Taking these results obtained above into consideration, only the microcapsules prepared with TDI were used hereafter to investigate the effect of supercooling prevention agent because of the highest heat storage density, the highest microencapsulation efficiency and the higher mechanical strength. 


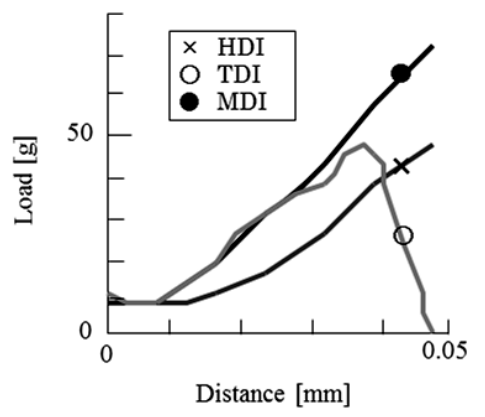

(a)

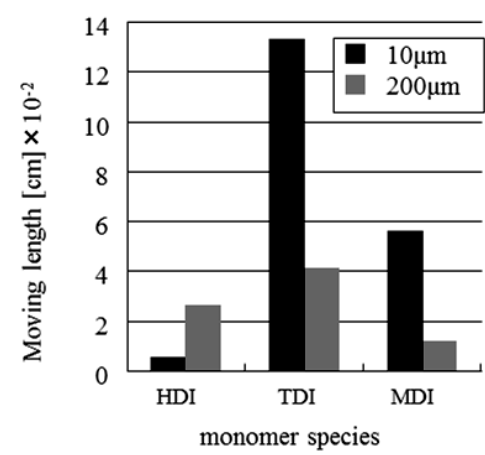

(b)

Figure 7. Measured results of mechanical strength and degree of shock absorbance.

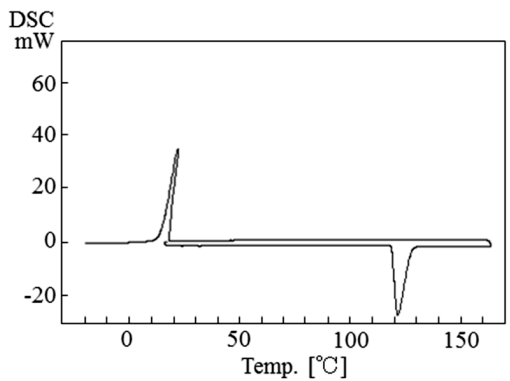

(a)

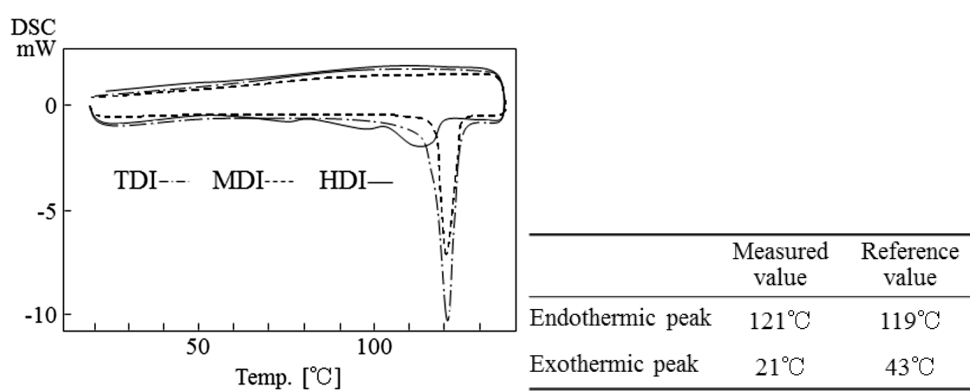

(b)

Figure 8. DSC curves of erythritol and microcapsules.

\subsection{Effects of Supercooling Prevention Agent and Diameter of Microcapsules}

It is well known that the supercooling phenomenon is strongly dependent on the volume where the phase change occurs, because whether sound smooth crystallization occurs or not is strongly affected by the volume. The hollow volume of microcapsule is determined by the diameter and shell thickness of microcapsule. In order to prevent the supercoolong phenomenon, it may be necessary to enlarge the hollow volume where the phase change occurs, namely to increase the diameter of microcapsules and to add the some appropriate supercooling prevention agents.

Figure 9 shows the DSC curve for erythritol without and with the supercooling prevention agent in order to investigate the effect of supercooling prevention agent. It was found that the exothermic peak point at $21^{\circ} \mathrm{C}$ shifted to ca. $100^{\circ} \mathrm{C}$ by adding potassium dihydrogen phosphate (2.5 wt\%) and calcium sulfate (2.5 wt\%) as the supercooling prevention agents.

On the other hand, Figure 10 shows the DSC curves for the microcapsules with the different diameters together with the SEM photographs. From these curves, it was found that the exothermic peaks were observed by increasing the diameters of microcapsules with $\left(\mathrm{T}=28^{\circ} \mathrm{C}\right)$ and without $\left(\mathrm{T}=18^{\circ} \mathrm{C}\right)$ the supercooling prevention agents and the exothermic peak at higher temperature $\left(\mathrm{T}=28^{\circ} \mathrm{C}\right)$ was observed by addition of the supercooling prevention agents. Also, the difference in the inner structure of microcapsules prepared without and with the supercooling prevention agents were not observed from the SEM photographs.

Figure 11 shows the dependences of heat storage density and the microencapsulation efficiency on the mean diameter of microcapsules and the addition of supercooling prevention agents. The heat storage density increased with the diameter and was not almost affected by addition of the supercooling prevention agents. Meanwhile, the microencapsulation efficiency increased from $50 \%$ to $90 \%$ with the mean diameter and could be slightly increased by addition of the supercooling prevention agents.

\section{Conclusions}

It was tried to prepare the microcapsules containing erythritol as a PCM by the interfacial polycondensation reaction method in order to obtain the fundamental informations required to apply to the latent heat storage. The 


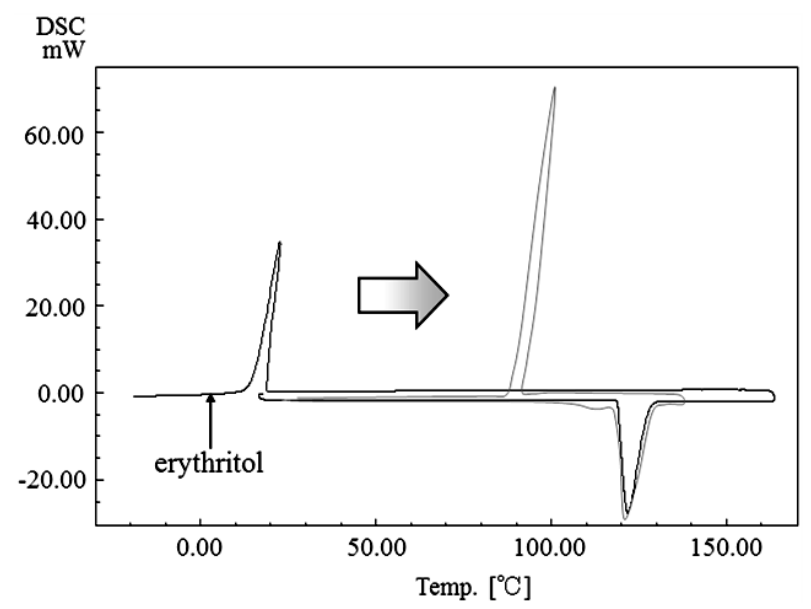

Figure 9. DSC curve of erythritol (effect of supercooling prevention agent).
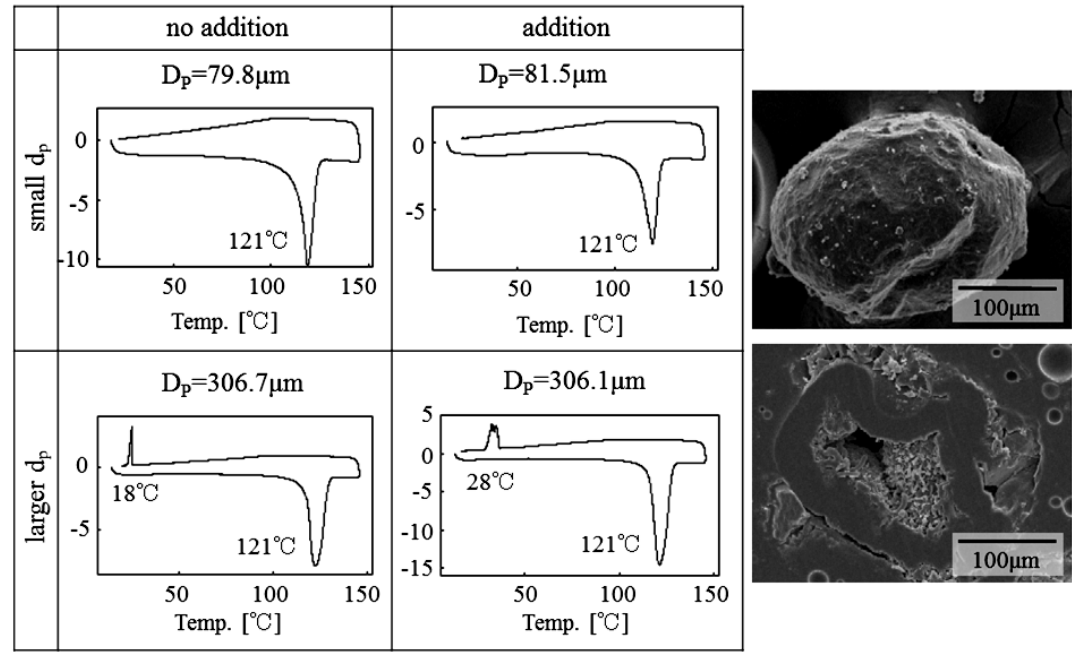

Figure 10. DSC curves of microcapsules with and without supercooling prevention agent and the SEM photographs.
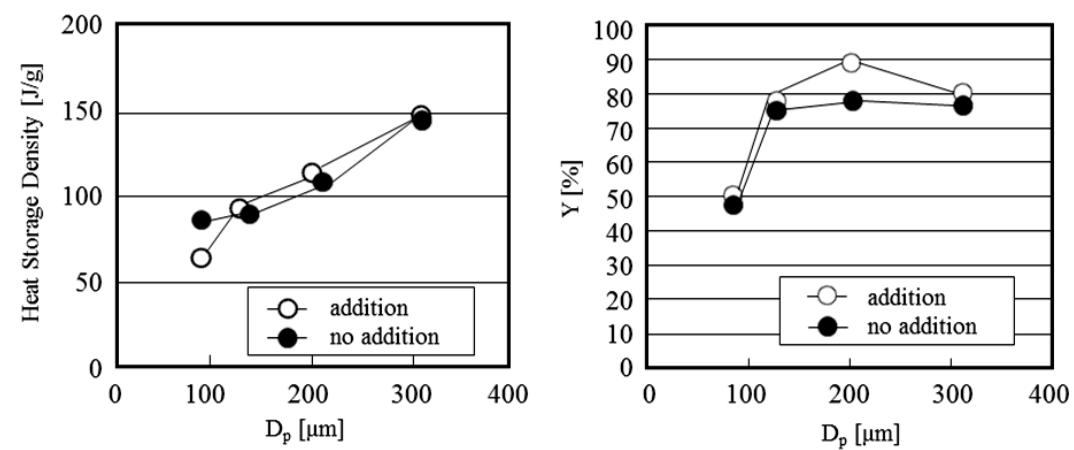

Figure 11. Dependences of heat storage density and microencapsulation efficiency on mean diameter.

following fundamental results were obtained:

1) The microcapsules could be prepared by using isocyanate species such as toluene diisocyanate, diphenyl methane diisocyanate, hexamethylenediisocyanate.

2) The microcapsules prepared with toluene diisocyanate showed the largest heat strage density and the larg- 
est microencapsulation efficiency.

3) Erythritol microencapsulated showed supercooling phenomenon.

4) The exothermic peaks were observed by increasing the microcapsule diameters and by adding the supercooling prevention agents such as potassium dihydrogen phosphate and calcium sulfate.

5) It is strongly desired that the superior supercooling prevention agents will be developed to use the water soluble PCMs such as erythritol and xyritol.

\section{References}

[1] Kondo, T. and Tanaka, M. (1975) Microcapsules (Preparation, Properties, Application). Sankyo Shuppan, Tokyo.

[2] Kondo, T. (1967) Saishin Maikurokapseruka Gijutsu (Microencapsulation Technique). TES, Tokyo.

[3] Tanaka, M. (2008) Key Point of Preparation of Nano/Microcapsules. Techno System Publishing Co. Ltd., Tokyo.

[4] Koishi, M., Eto, K. and Higure, H. (2005) (Preparation + Utilization) Microcapsules. Kogyo Chosakai, Tokyo.

[5] Yamagishi, Y., Sugeno, T., Takeuchi, H. and Pyatenko, A.T. (1998) Themal Characteristics of Supercooles Phase Change Materials inside Microcapsules. Netsu Bussei, 12, 10-17. http://dx.doi.org/10.2963/jitp.12.10

[6] Yamagishi, Y., Sugeno, T., Takeuchi, H. and Pyatenko, A.T. (1998) Forced Convection Heat Transfer with Microencapsulated Phase-Change-Material Slurries. Kagaku Kogaku Ronbunshu, 24, 104-110. http://dx.doi.org/10.1252/kakoronbunshu.24.104

[7] Yamagishi, Y., Takeuchi, H. and Pyatenko, A.T. (1999) Pyatenko, Characteristics of Microencapsulated PCM Slurry as a Heat-Transfer Fluid. AIChE Journal, 45, 696-707. http://dx.doi.org/10.1002/aic.690450405

[8] Cho, J.S., Kwon, A. and Cho, C.G. (2002) Microencapsulation of Octadecane as a Phase-Change Material by Interfacial Polymerization in an Emulsion System. Colloid and Polymer Science, 280, 260-266. http://dx.doi.org/10.1007/s00396-001-0603-X

[9] Zhang, X.X., Tao, X., Yick, K.I. and Wang, X.C. (2004) Structure and Thermal Stability of Microencapsulated PhaseChange Materials. Colloid and Polymer Science, 282, 330-336. http://dx.doi.org/10.1007/s00396-003-0925-y

[10] Su, J., Ren, L. and Wang, L. (2005) Preparation and Mechanical Properties of Thermal Energy Storage Microcapsules. Colloid and Polymer Science, 284, 224-228. http://dx.doi.org/10.1007/s00396-005-1368-4

[11] Zhaoa, C.Y. and Zhang G.H. (2011) Review on Microencapsulated Phase Change Materials (MEPCMs): Fabrication, Characterization and Applications. Renewable and Sustainable Energy Reviews, 15, 3813-3832. http://dx.doi.org/10.1016/j.rser.2011.07.019

[12] Kumar, R., Misra, M.K., Kumar, R., Gupta, D., Khatri, P.K., Tak, B.B. and Meena, S.R. (2011) Phase Change Materials: Technology Status and Potential Defence Applications. Defence Science Journal, 6, 576-582. http://dx.doi.org/10.14429/dsj.61.363

[13] Fortuniak, W., Slomkowski, S., Chojnowski, J., Kurjata, J., Tracz, A. and Mizerskas, U. (2013) Synthesis of a Paraffin Phase Change Material Microencapsulated in a Siloxane Polymer. Colloid and Polymer Science, 291, 725-733. http://dx.doi.org/10.1007/s00396-012-2782-z

[14] Tang, X., Li, W., Shi, H., Wang, X., Wang, J. and Zhang, X. (2013) Fabrication, Characterization, and Supercooling Suppression of Nanoencapsulated $n$-Octadecane with Methyl Methacrylate-Octadecyl Methacrylate Copolymer Shell. Colloid and Polymer Science, 291, 1705-1712. http://dx.doi.org/10.1007/s00396-013-2905-1

[15] Cheng, F., Wei, Y., Zhang, Y., Wang, F., Shen, T. and Zong, C. (2013) Preparation and Characterization of PhaseChange Material Nanocapsules with Amphiphilic Polyurethane Synthesized by 3-Allyloxy-1,2-propanediol. Journal of Applied Polymer Science, 130, 1879-1889. http://dx.doi.org/10.1002/app.39302

[16] Wang, T., Huang, J., Zhu, P. and Xiao, J. (2013) Fabrication and Characterization of Micro-Encapsulated Sodium Phosphate Dodecahydrate with Different Crosslinked Polymer Shells. Colloid and Polymer Science, 291, 2463-2468. http://dx.doi.org/10.1007/s00396-013-2973-2

[17] Shi, Y., Wu, Y., Zhu, L., Shentu, B. and Weng, Z. (2015) Preparation and Properties of Phase-Change Heat-Storage UV Curable Polyurethane Acrylate Coating. Journal of Applied Polymer Science, 132, 41266. http://dx.doi.org/10.1002/app.41266

[18] Stritih, U. and Novak, P. (1996) Solar Heat Storage Wall for Building Ventilation. Renewable Energy, 8, $268-271$. http://dx.doi.org/10.1016/0960-1481(96)88860-4

[19] Tyagi, V.V. and Buddhi, D. (2008) Thermal Cycle Testing of Calcium Chloride Hexahydrate as a Possible PCM for Latent Heat Storage. Solar Energy Materials \& Solar Cells, 92, 891-899. http://dx.doi.org/10.1016/j.solmat.2008.02.021

[20] Wang, T., Huang, J., Zhu, P. and Xiao, J. (2013) Fabrication and Characterization of Micro-Encapsulated Sodium 
Phosphate Dodecahydrate with Different Crosslinked Polymer Shells. Colloid and Polymer Science, 291, 2463-2468. http://dx.doi.org/10.1007/s00396-013-2973-2

[21] O’shima, E. and Tanaka, M. (1982) Coalescence and Breakup of Droplets in Suspension Polymerization of Styrene. Kagaku Kogaku Ronbunshu, 8, 86-90. http://dx.doi.org/10.1252/kakoronbunshu.8.86

[22] Hosogai, K. and Tanaka, M. (1992) Effect of Impeller Diameter on Mean Droplet Diameter in Circular Loop Reactor. The Canadian Journal of Chemical Engineering, 70, 645-653. http://dx.doi.org/10.1002/cjce.5450700405 
Scientific Research Publishing (SCIRP) is one of the largest Open Access journal publishers. It is currently publishing more than 200 open access, online, peer-reviewed journals covering a wide range of academic disciplines. SCIRP serves the worldwide academic communities and contributes to the progress and application of science with its publication.

Other selected journals from SCIRP are listed as below. Submit your manuscript to us via either submit@scirp.org or Online Submission Portal.
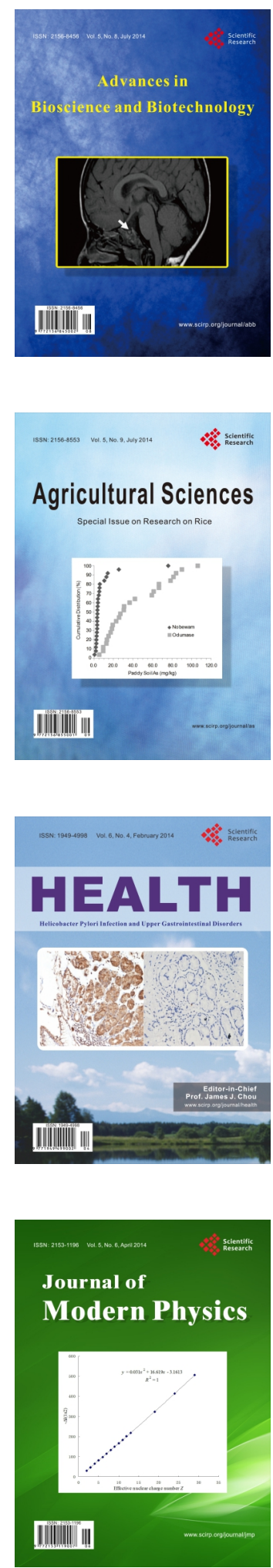
